SEÇÃO: ARTIGOS

\title{
PERCEPÇÃO DE DISCENTES DE FISIOTERAPIA SOBRE SUA FORMAÇÃO ACADÊMICA EM SAÚDE MENTAL
}

\author{
Murillo Nunes de Magalhães ${ }^{1}$ \\ Mara Cristina Ribeiro ${ }^{2}$
}

\section{RESUMO}

Atualmente têm sido exigidas do profissional fisioterapeuta novas habilidades para atuar no campo da saúde mental, o que requer que o ensino e a formação universitária incorporem essas mudanças. A pesquisa objetivou conhecer a percepção dos discentes de um curso de Fisioterapia de uma instituição de ensino superior do estado de Alagoas a respeito da formação em saúde mental. Utiliza a metodologia do estudo descritivo-exploratório de abordagem qualitativa, realizado com 12 participantes estagiários do último ano de formação. A produção dos dados foi realizada por meio de entrevista semiestruturada e essas informações foram submetidas à análise de conteúdo. Os alunos classificaram os conhecimentos adquiridos por meio da matriz curricular, relacionados ao campo da saúde mental, como pouco eficazes na prática; reconheceram a importância quanto à atuação do fisioterapeuta na demanda de cuidado e colocaram o preconceito e o estigma social da saúde mental como desafios a serem superados.

Palavras-chave: Saúde mental. Fisioterapia. Integralidade. Currículo.

\section{Como citar este documento - ABNT}

MAGALHÃES, Murillo Nunes de; RIBEIRO, Mara Cristina. Percepção de discentes de Fisioterapia sobre sua formação acadêmica em saúde mental. Revista Docência do Ensino Superior, Belo Horizonte, v. 10, e014800, p. 1-16, 2020 DOI: https://doi.org/10.35699/2237-5864.2020.14800.

Recebido em: 20/08/2019 Aprovado em: $11 / 10 / 2019$ Publicado em: 04/02/2020

\footnotetext{
${ }^{1}$ Universidade Estadual de Ciências da Saúde de Alagoas (UNCISAL), Maceió, AL, Brasil. ORCID: https://orcid.org/0000-0002-4097-5959.E-mail: murillofisio@hotmail.com.

${ }^{2}$ Universidade Estadual de Ciências da Saúde de Alagoas (UNCISAL), Maceió, AL, Brasil. ORCID: http://orcid.org/0000-0001-6963-8158. E-mail: marauncisal@yahoo.com.br.
} 


\section{PERCEPCIÓN DE ESTUDIANTES DE FISIOTERAPIA SOBRE SU ENTRENAMIENTO ACADÉMICO DE SALUD MENTAL}

\section{RESUMEN}

Actualmente, se ha requerido que los fisioterapeutas desarrollen nuevas habilidades en el campo de la salud mental, por lo que la educación y capacitación universitaria deben incorporar estos cambios. La investigación tuvo como objetivo conocer la percepción de los estudiantes de un curso de Fisioterapia de una institución de educación superior en el estado de Alagoas sobre la capacitación en salud mental. Utiliza la metodología del estudio descriptivo-exploratorio del enfoque cualitativo, realizado con 12 participantes en formación del último año de capacitación. La producción de datos se realizó a través de entrevistas semiestructuradas y las informaciones recogidas se sometieron a análisis de contenido. Los estudiantes calificaron el conocimiento adquirido a través del plan de estudios, relacionado con el campo de la salud mental, como ineficaz en la práctica; reconocieron la importancia del papel del fisioterapeuta en la demanda de atención y colocaron el prejuicio y el estigma social en la salud mental como desafíos a superar.

Palabras clave: Salud mental. Fisioterapia. Integralidad. Plan de estudios.

\section{PERCEPTION OF PHYSIOTHERAPY STUDENTS ABOUT THEIR ACADEMIC FORMATION IN MENTAL HEALTH}

\section{ABSTRACT}

Nowadays, new skills to work in the field of mental health have been required from the physiotherapy professionals, which requires that the university teaching and education incorporate these changes. This research aimed to know the perception of physiotherapy students from a higher education institution in the state of Alagoas, regarding of their academic formation in mental health. It uses the descriptive-exploratory study methodology with a qualitative approach, carried out with 12 interns from the last year of university. The data production was carried out through semi-structured interviews and this information was submitted to content analysis. Students classified the acquired knowledge through a curriculum matrix, related to the field of mental health, as ineffective in practice; they recognized the importance of the physiotherapist's role in the demand of care and placed bias and social stigma of mental health as challenges to be overcome.

Keywords: Mental health. Physiotherapy. Integrality. Curriculum. 
INTRODUÇÃO

A formação profissional em saúde no Brasil se mostra em um cenário desafiador, sendo indispensável a busca por enfoques que sensibilizem as pessoas a ultrapassar a concepção tecnicista, para que assim seja possível atender às reais necessidades da população. Isso se torna mais evidente no que tange à formação profissional para atender às pessoas com demandas em saúde mental, na qual o cuidado humanizado e ético torna-se necessário para a promoção integral à saúde (SINIAK et al., 2013).

Essa situação leva à busca da mudança de paradigmas da formação em Fisioterapia, que deve romper com o modelo focado na reabilitação física e formar profissionais com perfis generalistas, humanistas, críticos e reflexivos para o atendimento das necessidades sociais e populacionais que se modificam ao longo do tempo (ROCHA et al., 2012). Nesse aspecto, o ensino em saúde mental para os cursos de Fisioterapia representa um dos elementos mais complexos, por ser um campo de estudos marcado por subjetividades, pluralidades, intersetorialidades, interdisciplinaridade e transversalidade de saberes.

O exercício da fisioterapia no Brasil data do início do século $X X$, com a fundação do Departamento de Eletricidade Médica pelo Professor Raphael de Barros da Faculdade de Medicina da Universidade de São Paulo (MARQUES; SANCHES, 1994). No decorrer dos poucos anos de existência, a fisioterapia se estabeleceu como ciência da saúde, atuante em diversas áreas e ambientes profissionais, inclusive com ações eficientes em educação e promoção da saúde, descaracterizando-se da sua condição de profissão puramente reabilitadora, impregnada devido ao contexto histórico de sua criação (SILVA; ROS, 2007). Na atualidade, o fisioterapeuta possui perfil tanto para atuar em centros de referência em reabilitação, clínicas especializadas, hospitais e universidades quanto em serviços comunitários e generalistas, realizando, assim, sua função de educação, promoção e reabilitação em saúde nos mais diversos dispositivos da saúde (DIBAI FILHO, 2010).

Em 2002 o Conselho Nacional de Educação estabeleceu a resolução CNE/CES 4, de 19 de fevereiro, que instituiu as Diretrizes Curriculares Nacionais do Curso de Graduação em Fisioterapia (DCNs/Fisioterapia). Estas apontam que os conteúdos essenciais para o curso de graduação em Fisioterapia devem estar relacionados com todo o processo saúde-doença do cidadão, da família e da comunidade, articulados à realidade epidemiológica e profissional, proporcionando a integralidade das ações do cuidar em fisioterapia, quer nas alterações patológicas ou cinético-funcionais, quer nas repercussões psíquicas e orgânicas, cabendo ao profissional entender que as pessoas são dotadas de subjetividades e que o corpo não se dissocia da mente (CONSELHO NACIONAL DE EDUCAÇÃO, 2002).

As DCNs/Fisioterapia apontam que a atuação do profissional deve ser multiprofissional, interdisciplinar e transdisciplinar. Sua formação acadêmica, portanto, precisa proporcionar 
essa forma de atuação. Esta deve propiciar ao fisioterapeuta a construção de competências teórico-práticas para atuar em todos os níveis de atenção à saúde, com uma visão global e ampla da pessoa e do coletivo (TEIXEIRA, 2005). Nesse cenário, houve o redirecionamento do modelo de atenção com enfoque na integralidade humana.

No Brasil, um dos pilares da atenção básica é o princípio da integralidade, que se baseia em ações de promoção, prevenção de agravos e recuperação da saúde. Ela permite a percepção holística do sujeito, considerando o contexto histórico, social, político e familiar em que se insere. A atenção integral é, ao mesmo tempo, individual e coletiva, inviabilizando, portanto, ações dissociadas, evidenciando, assim, a necessidade de articulação entre a equipe multiprofissional (SOUZA et al., 2012, p. 453).

Ao considerar que os problemas de saúde mental estão cada vez mais presentes na vida cotidiana, o Ministério da Saúde aponta que no Brasil 23 milhões de pessoas (12\% da população) necessitam de algum atendimento em saúde mental (BRASIL, 2017). No mundo, os problemas de saúde mental ocupam cinco posições no ranking das dez principais causas de incapacidade, de acordo com a Organização Mundial da Saúde (OMS). Essa realidade, certamente, provocará impacto direto na qualidade de vida de muitas pessoas e, como consequência, na demanda por serviços da rede pública de saúde. 0 estudo aponta ainda uma escassez em todo o mundo de profissionais de saúde treinados nessa área e falta de investimento em instalações de saúde mental baseadas na comunidade (OMS, 2017).

Além disso, os profissionais devem estar atualizados e implicados com as novas demandas de cuidado advindas das portarias ministeriais do Sistema Único de Saúde (SUS), assim como com a adaptação dos conhecimentos teóricos e práticos inerentes à categoria profissional, relacionada às novas linhas de cuidado, a saber: Portaria no 483/2014, Portaria no 825/2016, Portaria no 3.588/2017, Resolução no 41/2018, que tratam das doenças crônicas e não transmissíveis; da atenção domiciliar no âmbito do SUS; da rede de atenção psicossocial e cuidados paliativos, dentre outras demandas de cuidado com que a saúde mental está relacionada e em que o profissional fisioterapeuta está inserido.

De acordo com a Portaria do Ministério da Saúde no 483, de 2014, que redefine a Rede de Atenção à Saúde das Pessoas com Doenças Crônicas no âmbito do SUS e estabelece diretrizes para a organização das suas linhas de cuidado, as ações devem estar voltadas para realizar o cuidado integral à saúde, em todos os pontos de atenção, por meio da realização de ações e serviços de promoção e proteção da saúde, prevenção de agravos, diagnóstico, tratamento, reabilitação, redução de danos e manutenção da saúde. Assim, garante-se a integralidade do cuidado, além de atuar no fortalecimento do conhecimento do usuário sobre suas doenças e ampliação da sua capacidade de autocuidado e autonomia (BRASIL, 2014). 
Portanto, é crescente a necessidade de inclusão das questões de saúde mental na perspectiva da formação acadêmica do fisioterapeuta no atendimento em hospitais gerais, ambulatórios e no âmbito da atenção básica, com objetivo de garantir ao futuro profissional capacidade para uma atuação comprometida com a qualidade e a integralidade da assistência. Considerando, principalmente, que os problemas de saúde mental não estão desarticulados de outros problemas de saúde, os profissionais fisioterapeutas devem desenvolver essas habilidades para a atenção integral em saúde.

De acordo com Silva, Pedrão e Miasso (2012), a pessoa em sofrimento mental, tanto por fatores psíquicos quanto por ação prolongada de medicamentos psicotrópicos, ou ainda pelo uso abusivo de álcool e outras drogas, apresenta dificuldades na realização de movimentos, tensão e rigidez muscular, alterações posturais, padrão respiratório irregular, comprometimento da expressão corporal, disfunções cognitivas e emocionais, danificando, assim, a funcionalidade e a percepção corporal, o que resulta em limitações e incapacidades. Os autores destacam, ainda, que a integração do fisioterapeuta nas equipes de saúde mental é de inteira importância, pois a fisioterapia poderá minimizar as alterações corporais exibidas pelas pessoas com transtornos mentais e auxiliará na reabilitação psicossocial dessas pessoas (MORALEIDA; NUNES, 2013).

Conhecer a importância das distintas e complementares visões sobre o usuário em saúde mental para o contexto da funcionalidade humana faz do fisioterapeuta um potencial aliado para exercer um impacto positivo sobre a função do indivíduo e incluir mudanças em aspectos físicos, cognitivos e sociais. Para tanto, se faz necessário que esse profissional, bem como as universidades, estejam com um olhar definido para essa temática (DALTRO; GARCIA, 2016).

Portanto, o ensino e a formação desses profissionais têm que acompanhar essas mudanças comportamentais da sociedade e entender o indivíduo que sofre como um todo, não apenas no aspecto da doença física. Há a necessidade, assim, de compreendê-la em seu sentido subjetivo, uma vez que, de acordo com os princípios da psicomotricidade, mente e corpo estão intimamente ligados por ações reflexas (FONSECA, 2010).

Esse contexto de mudanças no modelo de saúde mental no Brasil propõe não apenas garantir direitos e deveres a esses pacientes, mas também mudar paradigmas culturais. A mudança proposta é, portanto, cultural, de modo que a presença da saúde mental no ensino de Fisioterapia torna-se necessária e desafiadora. Nesse sentido, universidades e professores devem romper métodos antigos de ensino, para que esse se torne uma experiência construtiva de uma nova cultura assistencial às pessoas com doenças mentais e psíquicas (MAGNAGO; TAVARES, 2012; VILLELA; MAFTUM; PAES, 2013). 
O presente estudo é relevante, pois a necessidade da atenção psíquica em saúde é crescente. No entanto, percebe-se um descompasso entre o ensino em saúde mental e a prática de atuação no âmbito da fisioterapia. Por isso, mudanças são fundamentais na estrutura da matriz curricular para integrar o fisioterapeuta às necessidades de saúde da população, no âmbito da integralidade da assistência oferecida.

O objetivo da pesquisa foi conhecer a percepção dos discentes de um curso de Fisioterapia de uma universidade do estado de Alagoas a respeito da formação em saúde mental, a partir da atuação em estágio curricular.

\section{METODOLOGIA}

Trata-se de estudo exploratório e descritivo de abordagem qualitativa. Para o seu desenvolvimento foi realizada análise bibliográfica e documental, além de pesquisa de campo com uso das técnicas de entrevista e diário de campo. O protocolo de pesquisa foi submetido e aprovado pelo Comitê de Ética em Pesquisa, sob a CAAE 87526518.5.0000.5011 em 28 de maio de 2018.

O estudo foi desenvolvido com 12 estudantes do quinto ano do curso de graduação em Fisioterapia de uma universidade do estado de Alagoas que estavam cursando o estágio curricular em um hospital especializado em doenças infecto-contagiosas. O número de participantes foi determinado pela totalidade dos estagiários em Fisioterapia que passaram pelo local entre os meses de junho e novembro de 2018. Vale destacar que o local se caracteriza como uma unidade assistencial que recebe alunos de diversos cursos da área da saúde, sendo campo teórico-prático de estágio curricular desses cursos.

O instrumento utilizado para a produção dos dados foi a entrevista semiestruturada, guiada por um roteiro confeccionado pelos autores desta pesquisa e constituída por nove questionamentos específicos. Essas perguntas buscavam conhecer as percepções dos participantes tanto sobre saúde mental, no que se refere à preparação do aluno de Fisioterapia para atuar nesse campo, quanto sobre a participação do fisioterapeuta nas rotinas de atendimento do serviço, ao atender a demandas de pacientes de saúde mental em um hospital geral de doenças infecto-contagiosas. Além disso, havia questões relacionadas à formação em saúde mental do curso de graduação de Fisioterapia da referida universidade.

A entrevista foi gravada em forma de arquivo de áudio, mediante autorização prévia e, posteriormente, transcrita, o que permitiu uma análise de dados mais fidedigna. Para preservar a identidade dos participantes, foi atribuído às falas um código composto pela letra $\mathrm{A}$, seguido do número referente à ordem em que ocorreram as entrevistas em respeito ao sigilo dos participantes e às Resoluções 466/12 e 510/16 do Conselho Nacional de Saúde, 
do Ministério da Saúde. Assim, os voluntários foram submetidos a uma entrevista individual, gravada e transcrita em sua totalidade, realizada pelo pesquisador, e seu conteúdo foi investigado à luz da Análise de Conteúdo na modalidade temático-categorial para promover a imersão (BARDIN, 2011).

Por meio de incursões nos discursos, foi possível apreender a realidade que se esboça na prática diária desses participantes. A partir da decomposição dos textos em blocos organizados, com seus significados correspondentes, e da sua leitura exaustiva, foi possível a identificação de temas/categorias de análise. Logo se seguiu a fase de inferência dos resultados e interpretação, chegando assim à atribuição de significados aos conteúdos analisados, que vão além do material coletado. Dessa forma foram adotados referenciais teóricos próprios do ensino em saúde, bem como da especificidade da área da saúde mental.

\section{RESULTADOS E DISCUSSÃO}

Dois dos participantes eram do gênero masculino e dez, do gênero feminino. A idade dos participantes variou entre 22 e 27 anos. A análise do conteúdo das entrevistas realizadas sugere que a visão dos discentes de Fisioterapia sobre a formação e estudos em saúde mental perpassa por três dimensões: (I) Saúde mental na atualidade: necessidades e compromissos; (II) Saúde mental: resquícios de uma formação profissional em construção e (III) O fisioterapeuta no cuidado com a pessoa em sofrimento mental: transpondo barreiras.

\section{A saúde mental na atualidade: necessidades e compromissos}

O transtorno mental está em todos os níveis de atenção e todos os profissionais da saúde devem estar preparados para o cuidado com a população afetada, o que indica que a universidade deve dar o preparo para essa atuação. As falas abaixo ilustram como os participantes da pesquisa percebem a necessidade de ampliação da práxis profissional e a importância da saúde mental no contexto da formação:

"A gente tem visto hoje que a saúde mental, os transtornos mentais, eles têm sido muito presentes e muito prevalentes [...]. A questão de saúde mental pode trazer muitas comorbidades e é uma questão de saúde pública, então, enquanto profissional da saúde, eu preciso lidar também com a saúde mental" (A4).

"É importante porque, quando vamos para os estágios, a gente se depara com pacientes que têm problemas mentais, distúrbios mentais e, como nós não tivemos nenhum preparo durante a formação acadêmica, é nosso primeiro contato, a gente fica sem saber o que fazer" (A1). 
"Eu acho importante sim estudar esse tema, porque é um tema assim que está [...] em todos os ambientes, em todos os níveis, nível primário, secundário e terciário da saúde, que é onde o fisioterapeuta também está inserido. E, como tem que atender de forma integral, universalizada, acho importante sim estudar esse tema e de uma forma, vou dizer assim, generalista. Ao meu ver, cada distúrbio tem suas particularidades, mas, como a fisioterapia pode trabalhar de forma generalista [...], deve abordar sim os temas da saúde mental" (A9).

A humanidade sempre demonstrou ter dificuldade em lidar com as diferenças e com as dissonâncias do senso e da convivência comum. Na psiquiatria, por exemplo, o tratamento da loucura muitas vezes foi baseado na intolerância frente aos comportamentos dos doentes mentais, tendo na segregação dos indivíduos uma opção para afugentar o diferente e proteger a sociedade, assim como observa-se em algumas doenças na infectologia (CARDOSO; GALERA, 2011).

As falas demonstram que atualmente o campo da saúde mental é percebido de forma abrangente e que, por isso, as ações de cuidado não devem estar restritas aos serviços especializados. É nesse contexto que a fisioterapia se insere como integrante de uma equipe multiprofissional, responsável por serviços que compõem a saúde pública. Assim, associa seu fazer profissional com a integralidade do ser humano, que necessita de um olhar ampliado no contexto do processo saúde-doença.

O cuidado em saúde mental decorre de uma intrínseca relação entre os serviços de saúde, os seus profissionais, o paciente e a sua família, considerando as particularidades de cada contexto cultural, social e econômico. O domicílio é um espaço em que pessoas portadoras de doenças crônicas e outras afecções podem viver com boa qualidade de vida e manter a estabilidade da doença (CARDOSO; GALERA, 2011), desde que a família receba orientação e suporte dos serviços de saúde para isso, como se evidencia na seguinte fala:

"No estágio de saúde coletiva, tive a oportunidade de ver uma vez um
matriciamento do CAPS lá no posto, discutindo o caso de um paciente que
morava lá na comunidade e que inclusive eu atendia. Achei muito
interessante a preocupação da equipe do CAPS em ir até a comunidade para
conversar sobre o tratamento desse paciente, conversar tanto com os
profissionais do posto, quanto com algunsfamiliares" (A8).

O entendimento de que os serviços e os profissionais devem se articular é próprio das práticas comprometidas com a integralidade das ações de saúde. Ao valorizar uma experiência de cuidado ampliada, os estudantes mostram ter conhecimento, mesmo que empírico, de que sua atuação na perspectiva da saúde mental deve se dar em diferentes contextos. Evidencia-se, portanto, que a formação deve levar em conta a diversidade de atividades possíveis, considerando não apenas o usuário como sujeito exclusivo da atenção, 
mas os familiares, a comunidade e os outros serviços que possam se engajar nesse processo de cuidado.

\section{Saúde Mental: resquícios de uma formação profissional em construção}

O fisioterapeuta, conforme define o Conselho Federal de Fisioterapia e Terapia Ocupacional (COFFITO, 1975), é o profissional de saúde responsável pelas ações fisioterapêuticas com significativa atuação na sociedade, sempre em busca da globalidade funcional e biopsicossocial do ser humano. É um profissional cujo objeto de estudo é o movimento humano em todas as suas formas de expressão e potencialidades, tendo como objetivo profissional a preservação, o desenvolvimento e a restauração de órgãos, sistemas e funções.

A presente pesquisa, ao se aprofundar no estudo do atual projeto pedagógico do curso e em sua matriz curricular, verificou que este possui carga horária de 4.930 horas, dispostas em cinco anos, e apresenta em seu desenho curricular um elemento direcionador para a interprofissionalização, rompendo com a estrutura tradicional, centrada nas disciplinas e na formação específica de determinado perfil profissional. Para tanto, o curso está direcionado por cinco eixos integradores comuns à formação dos diversos profissionais da saúde, relativos a cada área de formação, que garantem e favorecem a articulação, a flexibilização e a mobilidade acadêmica, perpassando por todos os anos da graduação.

Observou-se também que entre as disciplinas ofertadas, a única que se aproxima de uma abordagem relativa à área de saúde mental está contemplada no eixo Saúde e Sociedade, a partir da disciplina de Introdução à Psicologia, oferecida nos semestres iniciais e caracterizada como generalista.

Nesse sentido, com o estudo documental da matriz curricular e do projeto pedagógico do curso, é possível afirmar que eles não apresentam temas mais aprofundados em relação à saúde mental e ao papel do fisioterapeuta no cuidado com a pessoa em sofrimento mental, o que pode ser constatado por meio das falas dos discentes da instituição que se queixam da falta de práticas em locais mais específicos da área.

"Seria um campo riquíssimo para ter certa experiência nessa prática, além de ter, na graduação, incluído saúde mental, poderíamos também ter um campo de estágio. Já que temos um hospital disponível pra isso e que trabalha com esse tipo de estudo, além de lá ter fisioterapeutas também" (A9).

Dessa maneira, faz-se necessário repensar a necessidade não apenas de mudança nas diretrizes que regem o curso, mas também nos locais de práticas ofertados para a formação. 
Ao serem indagados sobre a inserção curricular e o desenvolvimento da temática da saúde mental na formação dos fisioterapeutas, evidencia-se as seguintes ponderações:

"A matéria de Introdução à Psicologia, seria, digamos, uma tentativa de colocar a psicologia aplicada ao atendimento profissional [...] só que foi, assim, uma abordagem que não colaborou com o que seria importante. Falava sobre Freud, história da psicologia [...]. Quanto à abordagem do profissional de saúde diante de um paciente que tem uma alteração psicológica, a gente não tem essa base, não" (A4).

"Saúde mental foi pouquíssimo trabalhado, teve uma palestra na aula de Saúde e Sociedade, veio uma fisioterapeuta que trabalhava com educação especial pra essas pessoas e ela falou da atuação da fisio na saúde mental" (A9).

Diante das falas, percebe-se que a universidade não contempla, na matriz curricular do curso de Fisioterapia, o ensino na perspectiva do cuidado em saúde mental. Isso suscita um déficit na aprendizagem e na formação acadêmica dos discentes, o que certamente comprometerá a prática do atendimento integral ao paciente, uma vez que a relação entre a fisioterapia e a saúde mental continuará a ser negligenciada por falta de conhecimento teórico-prático.

As falas dos participantes do estudo evidenciam que a abordagem do tema saúde mental no curso de graduação em Fisioterapia ainda é escassa, e isso reflete na dificuldade que os discentes e profissionais da área possuem em argumentar sobre o assunto. Ao tentar fazê-lo, observa-se um conhecimento superficial e sempre reforçando sentimentos preconceituosos trazidos pela sociedade, o que contribui para a exclusão desses pacientes, conforme podemos constatar nas falas a seguir:

"A gente foi assistir uma palestra no hospital psiquiátrico e aí tivemos que passar por entre os pacientes e a sensação era de medo. Um profissional da saúde com medo de um paciente? A Fisioterapia precisa ter na matriz curricular a disciplina de saúde mental, e ela não deve ser trabalhada como uma disciplina de base móvel não, deve ser trabalhada de forma diferente [...]. Eu acredito que seria de forma sempre correlacionando a saúde mental com o fazer do fisioterapeuta" (A10).

"Como a gente não teve, aí, quando vai lidar com pacientes assim, vai assustado, a primeira vez você vai assustado, tipo [...] até por medo [...] de receber alguma [...] tipo esse paciente ter algum momento agressivo, por não saber lidar, pode gerar medo e esse medo pode atrapalhar a minha conduta com o paciente. Acho que se tivesse uma formação com conteúdos relacionados à saúde mental, acho que não teria esse impasse" (A7).

"[...] e eu fiquei sozinha, eu fiquei com medo, tive medo na hora, porque foi um comportamento ímpar do paciente [...]" (A8). 
O preconceito aparece como grande dificultador para a aproximação e o interesse de discentes e profissionais pela área da saúde mental. Além disso, destaca-se o medo como o sentimento geral no enfrentamento de situações que os estudantes vivenciam no cotidiano do cuidado em saúde quando se envolvem pacientes que sofrem algum transtorno mental.

Percebe-se que o estigma em relação ao paciente com demanda em saúde mental é consequência da falta de conhecimento específico sobre o tema, além do preconceito baseado nas concepções culturais que ainda permeiam a sociedade atual. $A$ incompreensão gerada pela falta de conhecimentos na área pode prejudicar o acolhimento desse paciente, 0 que impacta em seu tratamento (CANDIDO et al., 2012).

\title{
O fisioterapeuta no cuidado à pessoa em sofrimento mental: transpondo barreiras
}

A participação do fisioterapeuta no atendimento em saúde mental constitui um tema que merece discussão e produção de conhecimento nos contextos acadêmico, curricular e profissional da área de fisioterapia, uma vez que o assunto ainda parece desconhecido não somente pelos profissionais, mas por muitos trabalhadores da saúde em geral. Quando questionados sobre alguma experiência com demanda em saúde mental, a maioria dos participantes revelou já ter se deparado com a situação e não se sentir preparado no momento.

\begin{abstract}
"A maioria dos pacientes que eu peguei, eles já foram usuários de drogas, tinham quadros de abstinência. Inclusive, no primeiro dia que eu cheguei, o primeiro paciente que eu peguei, ele tava em um quadro de abstinência, eufórico, euforia, muito agitado, pedindo sempre usos de medicamentos, como uma tentativa talvez de diminuir o quadro de abstinência, agressivo [...]. Então foi bastante difícil, porque não é a realidade que o acadêmico de fisioterapia passa durante a graduação [...] nas práticas, nas vivencias... não é uma coisa que ele vê no dia a dia, então é bastante chocante na verdade, um impacto" (A10).

"Relatou que tava como se fossem uns mosquitos mordendo ele [...] e [...] tipo ele não realizou a fisioterapia nesse dia justamente por isso e [...] foi passado pra mim que poderia ser uma crise de abstinência" (A6).
\end{abstract}

De acordo com Camacho e Espírito Santo (2001), de uma maneira geral, as pessoas sentem medo do novo, do desconhecido, do que não Ihes é familiar. A relação vivenciada entre o aluno e o paciente e as descobertas provenientes do cuidar em saúde mental foram consideradas pelos participantes como algo novo na sua formação. Essa novidade pode implicar atitudes de preconceito e inabilidade profissional pelo fato de esses estudantes não terem o arcabouço teórico e prático da relação das doenças mentais com a fisioterapia. 
A partir dos relatos, constatamos a necessidade da qualificação da formação do fisioterapeuta com uma visão mais ampliada da saúde, pois, no decorrer de sua prática profissional, ele poderá deparar-se com uma pessoa em situação de sofrimento mental.

O fisioterapeuta deve então entender o indivíduo como um todo, pois, independentemente de sua situação de saúde-doença, seu corpo fala. O fato de os transtornos psiquiátricos terem uma origem psicológica não quer dizer que não se manifestem em sintomas físicos reais. Não é de se estranhar que esses pacientes venham a desenvolver dores, tensões musculares, má postura, restrições respiratórias, distúrbios da psicomotricidade ou inatividade (potencializada pelo uso de medicamentos psicotrópicos), problemas com os quais os profissionais fisioterapeutas devem estar atentos durante sua avaliação e atuar com diversas técnicas e métodos que a profissão dispõe. Entre elas estão: cinesioterapia, massoterapia, pilates, reeducação respiratória, técnicas de relaxamento, condicionamento físico, treinamento funcional, fisioterapia aquática (DALTRO; GARCIA, 2016).

Desse modo, as universidades devem exercer seu papel formador e orientador quanto à integralidade do cuidado e isso perpassa também pela formação acadêmica e profissional. 0 fisioterapeuta precisa ter o conhecimento acerca do seu papel no contexto do cuidado em saúde mental, visando a contribuir para a funcionalidade e a reinserção social das pessoas em sofrimento mental.

\section{CONCLUSÃO}

O tema do estudo está pautado no questionamento de como a formação do discente em Fisioterapia na área da saúde mental se apresenta e se relaciona com os cenários de prática onde o profissional está inserido, bem como em que contexto a formação desses discentes contribuem para a integralidade na assistência à saúde.

Os depoimentos dos participantes do estudo denotam que a formação do fisioterapeuta para atuar na saúde mental está deficiente, posto que a matriz curricular do curso, na instituição pesquisada, não apresenta esse conteúdo de maneira estruturada, ressaltando não haver preparação durante a graduação. Como consequência, perpetua-se essa carência na formação, o que prejudica a formação e a futura atuação profissional na perspectiva generalista e humanista, como apontam as DCNs do curso.

Como limitação do estudo, considera-se que, em função de essa pesquisa ter sido realizada em apenas uma universidade do estado de Alagoas, essa realidade pode não se confirmar em outros cursos. No entanto, seu resultado aponta para a necessidade de outros estudos, mais ampliados, serem desenvolvidos. 
Nesse sentido, os achados poderão ampliar a produção de conhecimentos no campo da fisioterapia na saúde mental, bem como encorajar a sua inserção na matriz curricular desse curso. Assim, a novidade da articulação da fisioterapia com o campo da saúde mental ganhará espaço, o que possibilita o repensar em relação à integralidade do ser humano nas ações de saúde.

O estudo, portanto, contribui para o debate acadêmico de docentes, discentes e profissionais da área de fisioterapia, em relação à formação e a inserção do fisioterapeuta no contexto do cuidado com saúde mental.

\section{REFERÊNCIAS}

BARDIN, Laurence. Análise de conteúdo. 4. ed. São Paulo: Edições, 2011.

BRASIL. Portaria no 483, de 1ㅇ de abril de 2014. Redefine a Rede de Atenção à Saúde das Pessoas com Doenças Crônicas no âmbito do Sistema Único de Saúde (SUS) e estabelece diretrizes para a organização das suas linhas de cuidado. Brasília, 2014. Disponível em: http://bvsms.saude.gov.br/bvs/saudelegis/gm/2014/prt0483_01_04_2014.html. Acesso em: 2 fev. 2019.

BRASIL. Portaria no 825, de 25 de abril de 2016. Redefine a Atenção Domiciliar no âmbito do Sistema Único de Saúde (SUS) e atualiza as equipes habilitadas. Brasília, 2016. Disponível em: http://bvsms.saude.gov.br/bvs/saudelegis/gm/2016/prt0825_25_04_2016.html. Acesso em: 2 fev. 2019.

BRASIL. Portaria no 3.588, de 21 de dezembro de 2017. Altera as Portarias de Consolidação n 3 e n ․ 6, de 28 de setembro de 2017, para dispor sobre a Rede de Atenção Psicossocial, e dá outras providências. Brasília, 2017. Disponível em:

http://bvsms.saude.gov.br/bvs/saudelegis/gm/2017/prt3588_22_12_2017.html. Acesso em: 2 fev. 2019.

BRASIL. Resolução $n=41$, de 31 de outubro de 2018. Dispõe sobre as diretrizes para a organização dos cuidados paliativos, à luz dos cuidados continuados integrados, no âmbito Sistema Único de Saúde (SUS). Brasília, 2018. Disponível em:

http://www.in.gov.br/web/guest/materia/-

/asset_publisher/Kujrw0TZC2Mb/content/id/51520746/do1-2018-11-23-resolucao-n-41-de31-de-outubro-de-2018-51520710. Acesso em: 2 fev. 2019.

CAMACHO, Alessandra Conceição Leite Funchal; ESPIRITO SANTO, Fátima Helena do. Refletindo sobre o cuidar e o ensinar na enfermagem. Revista Latino-Americana de Enfermagem, Ribeirão Preto, v. 9, n. 1, p. 13-17, jan. 2001.

CANDIDO, Maria Rosilene et al. Conceitos e preconceitos sobre transtornos mentais: um debate necessário. SMAD, Revista Eletrônica Saúde Mental Álcool Drogas (ed. port.), Ribeirão Preto, v. 8, n. 3, p. 110-117, dez. 2012. 
CARDOSO, Lucilene; GALERA, Sueli Aparecida Frari. O cuidado em saúde mental na atualidade. Revista da Escola de Enfermagem da USP, São Paulo, v. 45, n. 3, p. 687691, jun. 2011. Disponível em: www.ee.usp.br/reeusp/. Acesso em: 14 jan. 2019.

COFFITO. Conselho Federal de Fisioterapia e Terapia Ocupacional. Lei no 6.316, de 1975. Cria o Conselho Federal e os Conselhos Regionais de Fisioterapia e Terapia Ocupacional e dá outras providências. 1975. Disponível em:

http:/www.coffito.org.br/publicações/pub_view.asp.seção. Acesso em: 2 set. 2017.

CONSELHO NACIONAL DE EDUCAÇÃO. Resolução CNE/CES no 4, de 19 de fevereiro de 2002. Institui Diretrizes Curriculares Nacionais do Curso de Graduação em Fisioterapia. Diário Oficial da União, 4 mar. 2002, Brasília, DF.

CONSELHO NACIONAL DE SAÚDE. Resolução CNS no 466, de 12 de dezembro de 2012. Trata de pesquisas em seres humanos e atualiza a resolução 196. Diário Oficial da União, 13 jun. 2013, Brasília, DF.

CONSELHO NACIONAL DE SAÚDE. Resolução CNS no 510, de 07 de abril de 2016. Trata das especificidades das Ciências Humanas e Sociais. Diário Oficial da União, 24 de maio de 2016, Brasília, DF.

DALTRO, Manuela Carla Souza Lima; GARCIA, Viviane Valéria de Caldas Guedes. Fisioterapia na Saúde Mental. Patos: FIP, 2016.

DIBAI FILHO, Almir Vieira. Ensino superior em Fisioterapia no Brasil. Fisioterapia Brasil, [S.I.], v. 11, n. 5, p. 377-380, dez. 2010. ISSN 2526-9747. DOI:

http://dx.doi.org/10.33233/fb.v11i5.1425. Disponível em:

https://portalatlanticaeditora.com.br/index.php/fisioterapiabrasil/article/view/1425. Acesso em: 22 out. 2019.

FONSECA, Vitor da. Psicomotricidade: uma visão pessoal. Construção psicopedagógica, São Paulo, v. 18, n. 17, p. 42-52, dez. 2010. Disponível em:

http://pepsic.bvsalud.org/scielo.php?script=sci_arttext\&pid=S1415-

69542010000200004\&lng=pt\&nrm=iso. Acesso em: 17 out. 2019.

MAGNAGO, Carine; TAVARES, Claudia Mara de Melo. O ensino de enfermagem psiquiátrica nas universidades públicas do estado do Rio de Janeiro. Revista Eletrônica de Enfermagem, [online], v. 14, n. 1, p. 50-58, jan./mar. 2012. Disponível em:

https://www.fen.ufg.br/revista/v14/n1/pdf/v14n1a06.pdf. Acesso em: 1 jul. 2019.

MARQUES, Amélia Pasqual; SANCHES, Eugênio Lopes. Origem e evolução da Fisioterapia: aspectos históricos e legais. Revista de Fisioterapia da Universidade de São Paulo, São Paulo, v. 1, n. 1, p. 5-10, nov. 1994.

MORALEIDA, Fabiana Resende de Jesus; NUNES, Ana Carla Lima. Cuidado em saúde mental: perspectiva de atuação fisioterapêutica. Revista Fisioterapia e Saúde Funcional, Fortaleza, v. 2, n. 1, p. 3-5, jan./jun. 2013. Disponível em: 
http://periodicos.ufc.br/fisioterapiaesaudefuncional/article/view/20551. Acesso em: 4 fev. 2019.

OMS. ORGANIZAÇÃO MUNDIAL DA SAÚDE. Atlas de Saúde Mental 2017. Genebra. Organização Mundial da Saúde. 2017. Disponível em:

https://www.paho.org/bra/index.php?option=com_content\&view=article\&id=5694:saudemental-e-necessario-aumentar-recursos-em-todo-o-mundo-para-atingir-metasglobais\&Itemid=839. Acesso em: 2 fev. 2019.

ROCHA, Aurora Tatiana Soares et al. Cuidado em Saúde Mental: um sistema para ensino em Enfermagem. Journal of Health Informatics, [online], v. 4, n. esp., p. 103-107, dez. 2012. Disponível em: http://www.jhi-sbis.saude.ws/ojs-jhi/index.php/jhi-sbis/article/view/. Acesso em: 2 jul. 2019.

SILVA, Daysi Jung da; ROS, Marco Aurélio da. Inserção de profissionais de fisioterapia na equipe de saúde da família e Sistema Único de Saúde: desafios na formação. Ciência \& Saúde Coletiva, Rio de Janeiro, v. 12, n. 6, p. 1673-1681, dez. 2007.

DOI: http://dx.doi.org/10.1590/S1413-81232007000600028. Disponível em: http://www.scielo.br/scielo.php?script=sci_arttext\&pid=S1413$81232007000600028 \&$ Ing=en\&nrm=iso. Acesso em: 20 abr. 2019.

SILVA, Soraya Batista da; PEDRAO, Luiz Jorge; MIASSO, Adriana Inocenti. O Impacto da fisioterapia na reabilitação psicossocial de portadores de transtornos mentais. SMAD, Revista Eletrônica Saúde Mental Álcool e Drogas (ed. port.), Ribeirão Preto, v. 8, n. 1, p. 3440, abr. 2012. Disponível em: http://pepsic.bvsalud.org/scielo.php?script=sci_arttext\&pid=S1806$69762012000100006 \&$ lng=pt\&nrm=iso. Acesso em: 15 jan. 2019.

SINIAK, Débora Schlotefeldt et al. Relato de experiência de estágio de docência na área de enfermagem psiquiátrica e saúde mental. Ciência, Cuidado e Saúde, Maringá, v. 12, n. 3, p. 593-598, jul./set. 2013. Disponível em:

http://periodicos.uem.br/ojs/index.php/CiencCuidSaude/article/view/20700. Acesso em: 02 jul. 2019.

SOUZA, Marcio C. et al. Integralidade na atenção à saúde: um olhar da Equipe de Saúde da Família sobre a fisioterapia. O Mundo da Saúde, São Paulo, v. 36, n. 3, p. 452-460, 2012. Disponível em:

http://bvsms.saude.gov.br/bvs/artigos/mundo_saude/integralidade_antecao_saude_olhar_ equipe.pdf. Acesso em: 2 set. 2017.

TEIXEIRA, Ricardo Rodrigues. Humanização e atenção primária à saúde. Ciência \& Saúde Coletiva, Rio de Janeiro, v. 10, n. 3, p. 585-597, sep. 2005. DOI:

http://dx.doi.org/10.1590/S1413-81232005000300016. Disponível em:

http://www.scielo.br/scielo.php?script=sci_arttext\&pid=S1413-

81232005000300016\&lng=en\&nrm=iso. Acesso em: 20 mar. 2019. 
VILLELA, Juliane Cardoso; MAFTUM, Mariluci Alves; PAES, Márcio Roberto. O ensino de saúde mental na graduação de enfermagem: um estudo de caso. Texto contexto enfermagem, Florianópolis, v. 22, n. 2, p. 397-406, abr./jun. 2013. DOI: http://dx.doi.org/10.1590/S0104-07072013000200016. Disponível em: http://www.scielo.br/scielo.php?script=sci_arttext\&pid=S010407072013000200016\&lng=en\&nrm=iso. Acesso em: 8 fev. 2019.

\section{Murillo Nunes de Magalhães}

Mestre em Ensino na Saúde e Tecnologia - Programa de Pós-Graduação Stricto Sensu UNCISAL (2019). Possui especialização em Saúde Pública pela UFAL (2016); especialização em Fisioterapia Neurofuncional pela FIR (2008); graduação em Fisioterapia pelo CESMAC (2006) e capacitação em Saúde Mental (2019). Atua principalmente nos seguintes temas: saúde pública, fisioterapia hospitalar e saúde mental.

murillofisio@hotmail.com

\section{Mara Cristina Ribeiro}

Membro fundadora da Academia Alagoana de Educação. Possui doutorado em Ciências (2012) e mestrado em Enfermagem Psiquiátrica (2005), ambos pela Universidade de São Paulo (USP). Possui especialização em Saúde Pública pela Universidade de Ribeirão Preto (2002) e graduação em Terapia Ocupacional pela Universidade de São Paulo (1996). É professora titular da Universidade Estadual de Ciências da Saúde de Alagoas (UNCISAL). marauncisal@yahoo.com.br 